\title{
Desigualdade de acesso à Educação Infantil: uma análise da meta 1 do PNE na região metropolitana de Maringá
}

\section{Inequality of access to Early Childhood education: an analysis of goal 1 of the Brazilian National Education Plan in the metropolitan region of Maringá City, Paraná State, Brazil}

\author{
Ângela Scalabrin Coutinho* \\ Thiago Alves**
}

\begin{abstract}
RESUMO
O artigo apresenta uma análise dos 26 municípios que compõem a região metropolitana de Maringá (RMM) quanto ao cumprimento da meta 1 do Plano Nacional de Educação (PNE), com destaque para a desigualdade e o tamanho do desafio dos municípios. O estudo utilizou os microdados do Censo demográfico/IBGE 2010, Censo Escolar/Inep 2010 e 2016 e dados da estimativa populacional para 2016 fornecidos pelo IBGE. Foram calculadas 'taxa de atendimento', 'taxa de escolarização líquida', 'percentual de variação das matrículas 2010-2016' e 'Demanda por novas matrículas e turmas' para cada município. Os resultados evidenciam expressiva desigualdade de acesso à educação para as crianças de 0 a 5 anos entre os municípios; mostram uma expansão no período de 2010 a
\end{abstract}

* Universidade Federal do Paraná. Curitiba, Paraná, Brasil. E-mail: angelamscoutinho@ gmail.com. https://orcid.org/0000-0002-3709-8561.

** Universidade Federal de Goiás. Goiânia, Goiás, Brasil. E-mail: thiagoalves.edu@gmail. com. https://orcid.org/0000-0002-5746-3386. 
2016 de 5.099 matrículas (40\%) para as crianças de 0 a 3 anos e de 2.008 matrículas $(12,2 \%)$ para as crianças de 4 e 5 anos; e que, após a expansão, em 2016, quase todos os municípios estavam próximos de atingir a meta de universalização do acesso para a população de 4 e 5 anos, mas, quanto ao atendimento de 0 a 3 anos, sete municípios estavam abaixo da meta de $50 \%$ definida no PNE. O quadro diversificado identificado na RMM quanto ao acesso das crianças de 0 a 5 anos à educação reforça a importância do monitoramento dos indicadores de acesso para orientar o planejamento e gestão das políticas educacionais nos municípios.

Palavras-chave: Educação Infantil. Plano Nacional de Educação. Desigualdade de acesso. Indicadores educacionais. Políticas Educacionais.

\begin{abstract}
The article presents an analysis of the 26 municipalities that compose the Metropolitan Region of Maringá City (MRM) - Paraná State, Brazil, regarding the compliance of goal number 1 of the Brazilian National Education Plan (NEP). It aims to highlight the inequality and the size of the municipalities' challenge. Thus, the study used the microdata of the Brazilian Demographic Census / IBGE 2010, and Brazilian School Census / Inep 2010 and 2016 as well as data from the Brazilian population estimate for 2016 provided by IBGE. The 'attendance rate', 'net enrollment rate', 'percentage of variation of enrollments 2010-2016' and 'Demand for new enrollments and classes' for each municipality were calculated. The results show: i. a significant inequality of access to education for children from 0 to 5 years of age among municipalities; ii. an expansion in the period from 2010 to 2016 of 5,099 enrollments (40\%) for children from 0 to 3 years of age and 2,080 enrollments (12.2\%) for children of 4 and 5 years of age; and that, after the expansion in 2016, iii. almost all municipalities were close to meeting the goal of universal access for children in pre-school age, however, for children from 0 to 3 years of age, seven municipalities were below the target of $50 \%$ defined by the NEP. The diversified framework identified in the MRM regarding the access of children from 0 to 5 years of age to education reinforces, therefore, the importance of monitoring access
\end{abstract}


indicators to guide the planning and management of educational policies in municipalities.

Keywords: Early Childhood Education. Brazilian National Education Plan. Inequality of access. Educational indicators. Educational Policies.

\section{Introdução}

A meta 1 do Plano Nacional de Educação (PNE), Lei n. 13.005/2014, prevê "universalizar, até 2016, a educação infantil na pré-escola para as crianças de 4 (quatro) a 5 (cinco) anos de idade e ampliar a oferta de educação infantil em creches de forma a atender, no mínimo, $50 \%$ (cinquenta por cento) das crianças de até 3 (três) anos até o final da vigência deste PNE" (BRASIL, 2014, p. 03). E, embora o Art. 211 da Constituição Federal (BRASIL, 1988, p. 88) estabeleça que "a União, os Estados, o Distrito Federal e os Municípios organizarão em regime de colaboração seus sistemas de ensino", a oferta da educação infantil é responsabilidade prioritária dos municípios, segundo a Lei de Diretrizes e Bases da Educação (LDB), Lei n. 9.394/1996 (BRASIL, 1996).

Considerando que o prazo para a universalização da pré-escola expirou em 2016 e que, até 2024, no mínimo, 50\% das crianças de 0 a 3 anos deverão estar matriculadas em creches, o objetivo deste artigo é problematizar o tamanho do desafio dos 26 municípios que compõem a Região Metropolitana de Maringá $(\mathrm{RMM})^{1}$, no estado do Paraná, para cumprir a meta 1 do PNE.

O principal desafio para o monitoramento do alcance da meta no nível de municípios se dá pela inexistência de dados sobre o número de crianças nas faixas etárias específicas da Educação Infantil (creche: 0 a 3 anos e pré-escola: 4 e 5 anos). A base de dados populacional com informações no nível munici-

1 Essa região foi instituída pela Lei Complementar Estadual 83/1998 e é formada por 26 municípios: Maringá, Sarandi, Marialva, Mandaguari, Paiçandu, Ângulo, Iguaraçu, Mandaguaçu, Floresta, Doutor Camargo, Itambé, Astorga, Ivatuba, Bom Sucesso, Jandaia do Sul, Cambira, Presidente Castelo Branco, Flórida, Santa Fé, Lobato, Munhoz de Mello, Floraí, Atalaia, São Jorge do Ivaí, Ourizona e Nova Esperança. 
pal mais recente disponível é o Censo Demográfico 2010, pois, nesta década, ao contrário das anteriores, a Fundação Instituto Brasileiro de Geografia e Estatística (IBGE) não realizou a contagem da população no período intercensitário ${ }^{2}$. Vale ressaltar que a Pesquisa Nacional por Amostra de Domicílio (PNAD/IBGE), embora seja realizada anualmente, não permite desagregar os resultados no nível dos municípios ${ }^{3}$. A alternativa para realização dos estudos passa a ser a utilização de projeções populacionais, ainda que essas tenham um nível de imprecisão que não pode ser estimado, uma vez que projeções populacionais com alto nível de precisão requerem o acompanhamento das taxas de natalidade, mortalidade e de migração de cada município para cada faixa etária de interesse ao longo dos anos ${ }^{4}$.

Considerando esses limites, neste trabalho, foram utilizados os dados da população nas faixas etárias relativas à creche e à pré-escola oriundos do Censo 2010 (por ser fonte de dados no nível municipal mais recente disponível) e a projeção populacional com parâmetros fornecidos pelo IBGE para o ano de 2016 (ano estabelecido pela Emenda Constitucional 59/2009 para a universalização do atendimento das crianças de 4 a 5 anos na pré-escola).

Assim, diante da possibilidade de replicação dos procedimentos metodológicos propostos, acredita-se que a possível contribuição deste artigo consiste mais em ressaltar a importância do esforço de monitoramento da garantia do direito à educação na perspectiva da meta 1 do PNE 2014-2024 nos municípios com os dados disponíveis, ainda que com resultados aproximados, do que em fazer afirmações em definitivo sobre a situação das localidades analisadas. Nesse sentido, acredita-se que a utilização dos dados disponíveis,

2 O IBGE deve, por força de lei, informar anualmente a população dos municípios (Lei Complementar $n^{\circ}$ 59/1988). Para isso, além das estimativas anuais baseadas na Pesquisa Nacional por Amostra de Domicílio (PNAD), realizava a Contagem da População como forma de fornecer informações mais precisas no período intercensitário, uma vez que a precisão de estimativas populacionais é menor na medida em que os anos se afastam do último recenseamento. A primeira contagem aconteceu em 1996 e a segunda em 2007. Na década corrente, essa contagem não ocorreu.

3 A PNAD é realizada anualmente desde 1971 nos anos que não ocorre o censo decenal. A amostra da pesquisa é consideravelmente menor do que a do Censo Demográfico. Por isso, os resultados são desagregados apenas para o nível dos Estados, Distrito Federal e as maiores regiões metropolitanas do país.No Paraná, apenas para a região metropolitana da capital. A partir de 2015, o IBGE passou a realizar a "PNAD Contínua" que coleta dados com periodicidade variada (mensal, trimestral ou anual) a depender do tema: trabalho, fecundidade, educação etc., mas manteve o mesmo nível de desagregação dos resultados.

4A Fundação Seade, instituto de estatística e pesquisa do estado de São Paulo (equivalente ao Ipardes no Paraná) faz o acompanhamento das componentes demográficas por meio de um sistema de informação que coleta dados dos cartórios daquele estado. Desse modo, aquele órgão consegue fazer projeções populacionais no nível dos municípios para diversas faixas etárias. 
além de suscitar novas análises locais mais detalhadas com outras fontes, é uma forma de dar consequência aos esforços dos levantamentos realizados pelo Instituto Nacional de Estudos e Pesquisas Educacionais Anísio Teixeira (Inep) e IBGE, que visam subsidiar o planejamento, monitoramento e avaliação de políticas públicas.

A partir desta introdução, o artigo está estruturado em três seções. A seguir, são apresentados os procedimentos metodológicos. Depois, é apresentado um quadro do atendimento da educação infantil em 2010 e 2016 nessa RMM e, por fim, algumas considerações são apresentadas na última seção.

\section{Aspectos metodológicos}

É importante considerar que os indicadores educacionais (assim como os demais indicadores sociais) são medidas com potencial de apontar, traduzir, aproximar, descrever ou revelar características e aspectos dos fenômenos sociais (JANNUZZI, 2005). Ou seja, por limitações intrínsecas aos elementos que os compõem (fonte de dados, fórmula de cálculo, conteúdo das variáveis etc.), os indicadores são medidas síntese que captam apenas alguns aspectos da realidade.

Nesse sentido, o diagnóstico da situação dos municípios da RMM nos anos de 2010 e 2016 quanto à garantia do direito à educação infantil na dimensão do acesso, bem como a análise do tamanho do desafio de cada município para o cumprimento da meta 1 , foram realizados por meio do cálculo dos seguintes indicadores de: (a) taxa de atendimento escolar; e (b) taxa de

5 Verifica-se que os dois indicadores utilizam o termo "escolarização" em seus nomes. Todavia, o artigo trata especificamente da educação infantil e os autores são contrários à ideia de escolarização das crianças nessa etapa de ensino. Por isso, doravante, ao longo do artigo, será utilizado o termo 'taxa de atendimento' (ao invés de 'taxa de atendimento escolar') e a sigla TEL como referência à "taxa de escolarização líquida".

6 O dicionário de indicadores educacionais do Instituto Nacional de Estudos e Pesquisas Educacionais Anísio Teixeira (Brasil, 2004) reúne 11 indicadores de 'acesso e participação'. Esses indicadores visam "medir" diferentes aspectos da inserção da população no sistema educacional. Apesar do Inep não ter lançado novas versões do referido dicionário, o instituto tem avançado em novas formas de cálculo dos indicadores educacionais. Por exemplo, no Relatório de Monitoramento do $1^{\circ}$ e $2^{\circ}$ ciclos das Metas do Plano Nacional de Educação 2014-2024 (BRASIL, 2016, 2018), o instituto calcula a 'taxa de atendimento escolar' utilizando somente as bases de dados populacionais (nesse caso, a Pesquisa Nacional por Amostra de Domicílio - PNAD) e, não mais, as bases do Censo Escolar e as bases populacionais conjuntamente como em Brasil (2004). 
escolarização líquida (TEL) ${ }^{5}$. Esses dois indicadores foram adotados por serem medidas amplamente adotadas para análise do acesso à educação, inclusive em análises comparativas internacionais como OECD (2016). Neste artigo, eles foram calculados com base nas propostas metodológicas do Inep publicadas em Brasil $(2004,2016,2018)^{6}$. Adicionalmente, com vistas aos propósitos específicos do artigo, foram calculados: (c) o percentual de variação das matrículas (para analisar a dinâmica das matrículas no período 2010-2016); e a (d) demanda por novas turmas de creche e pré-escola (como forma de estimar, grosso modo, o esforço do poder público local quanto à demanda de novas salas de aula e profissionais para realizar a expansão da oferta necessária). O quadro 1 apresenta as principais definições, detalhamentos metodológicos e referências dos quatro indicadores utilizados.

A taxa de atendimento expressa o percentual da população, em determinada faixa etária, que afirma estar frequentando escola ou creche ${ }^{7}$. É baseada em uma declaração da população e não reflete, necessariamente, o número de matrículas da rede de ensino local. O indicador é calculado a partir da divisão do número de crianças em determinada faixa etária cuja família declarou que está frequentando a escola ou creche pelo número de crianças na faixa etária correspondente (população). As fontes de dados utilizadas são as pesquisas domiciliares do IBGE (PNAD ou Censo demográfico). Nesse estudo, foram calculadas as taxas de atendimento para as faixas de 0 a 3 anos e 4 e 5 anos (separadamente) para os 26 municípios da RMM a partir dos dados do Censo demográfico 2010 com intuito de diagnosticar a situação no ano da única fonte que permite esse tipo de análise em nível municipal.

7 No questionário do Censo 2010 havia a seguinte questão: Frequenta escola ou creche? (V0628). As possibilidades de resposta eram: 1 - Sim, pública; 2 - Sim, particular; 3 - Não, já frequentou; 4 - Não, nunca frequentou. 


\section{QUADRO 1 - SINOPSE TÉCNICA DE INDICADORES PARAANÁLISE DO ACESSO À EDUCAÇÃO INFANTIL}

\begin{tabular}{|c|c|c|c|c|}
\hline $\begin{array}{l}\text { Indica- } \\
\text { dor }\end{array}$ & Interpretação & Fórmula & $\begin{array}{l}\text { Fonte } \\
\text { dos } \\
\text { dados }\end{array}$ & $\begin{array}{l}\text { Refe } \\
\text { rên- } \\
\text { cia }\end{array}$ \\
\hline $\begin{array}{l}\text { Taxa de } \\
\text { atendi- } \\
\text { mento }\end{array}$ & $\begin{array}{l}\text { Expressa o } \\
\text { percentual da } \\
\text { população de } \\
\text { determinada } \\
\text { faixa etária que } \\
\text { frequenta creche ou } \\
\text { escola. }\end{array}$ & $\begin{array}{l}\quad \mathrm{TA}_{1}=\frac{p p_{i}}{p_{i}} \times 100 \\
\text { Onde: } \\
\text { TA = Taxa de atendimento } \\
\mathrm{PF}=\text { População na faixa etária i que frequenta } \\
\text { creche ou escola } \\
\mathrm{P}=\text { População na faixa etária i } \\
\mathrm{i}=\text { Faixa etária }(0 \text { a } 3 ; 4-5 \text { anos })\end{array}$ & $\begin{array}{l}\text { Censo } \\
2010\end{array}$ & $\begin{array}{l}\text { Brasil } \\
(2016, \\
2018) ; \\
\text { IBGE } \\
(2016)\end{array}$ \\
\hline $\begin{array}{l}\text { Taxa de } \\
\text { escolariza- } \\
\text { ção líquida } \\
\text { (TEL) }\end{array}$ & $\begin{array}{l}\text { Expressa o } \\
\text { percentual de } \\
\text { pessoas de } \\
\text { determinada faixa } \\
\text { etária matriculadas } \\
\text { na etapa de ensino } \\
\text { teoricamente } \\
\text { adequada à } \\
\text { faixa etária em } \\
\text { relação ao total da } \\
\text { população na faixa } \\
\text { etária. }\end{array}$ & $\begin{array}{l}\quad \mathrm{TEL}_{\mathrm{k} 1}=\frac{M_{k i}}{P_{k i}} \times 100 \\
\text { Onde: } \\
\mathrm{TEL}=\text { Taxa de escolarização líquida } \\
\mathrm{M}=\text { Número de matrícula na etapa } \mathrm{k} \text { de pessoas } \\
\text { na faixa etária i } \\
\mathrm{P}=\text { População na faixa etária i corresponde à } \\
\text { etapa } \mathrm{k} \\
\mathrm{i}=\text { faixa etária }(0 \text { a } 3 ; 4-5) \\
\mathrm{k}=\text { Segmento da Educação Infantil (creche; pré- } \\
\text { escola) }\end{array}$ & $\begin{array}{l}\text { Censo } \\
\text { Escolar } \\
2010 \mathrm{e} \\
2016 ; \\
\text { Censo } \\
2010 ; \\
\text { projeção } \\
\text { da po- } \\
\text { pulação } \\
\text { de } 2010 \\
\text { com base } \\
\text { em IBGE } \\
\text { (2016) }\end{array}$ & $\begin{array}{l}\text { Brasil } \\
(2004)\end{array}$ \\
\hline $\begin{array}{l}\text { Percentual } \\
\text { de varia- } \\
\text { ção das } \\
\text { matrículas }\end{array}$ & $\begin{array}{l}\text { Expressa o } \\
\text { percentual de } \\
\text { crescimento ou } \\
\text { descrecimento } \\
\text { do número de } \\
\text { matrículas em } \\
\text { determinado } \\
\text { período. }\end{array}$ & 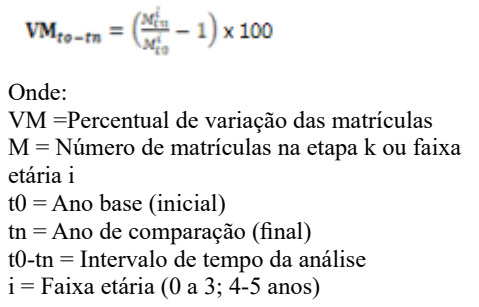 & $\begin{array}{l}\text { Censo } \\
\text { Escolar } \\
2010 \mathrm{e} \\
2016\end{array}$ & Autores \\
\hline $\begin{array}{l}\text { Demanda } \\
\text { por novas } \\
\text { turmas }\end{array}$ & $\begin{array}{l}\text { Expressa o número } \\
\text { de novas turmas } \\
\text { para atender e } \\
\text { demanda por } \\
\text { matrículas com } \\
\text { vistas a cumprir } \\
\text { as metas de oferta } \\
\text { educacional. }\end{array}$ & $\begin{array}{l}\quad \mathrm{D}_{k}=\frac{M_{k}}{\lambda T_{k}} \times 100 \\
\text { Onde: } \\
\mathrm{D}=\text { Demanda por novas turmas } \\
\mathrm{M}=\text { Estimativa de novas matrículas na estapa } \mathrm{k} \\
\mathrm{AT}=\text { Número máximo de alunos por turma na } \\
\text { etapa } \mathrm{k} \text { (creche }=12 ; \text { pré-escola }=22 \text { ) } \\
\mathrm{k}=\text { Segmento da Educação Infantil (chreche; } \\
\text { pré-escola) }\end{array}$ & $\begin{array}{l}\text { Estima- } \\
\text { tivas de } \\
\text { novas } \\
\text { turmas }\end{array}$ & Autores \\
\hline
\end{tabular}

FONTE: Elaborado pelos autores. 
faixa etária de 0 a 3 ou 4 e 5 anos matriculadas no segmento da educação infantil correspondente à faixa etária (creche ou pré-escola, respectivamente). Os resultados são apresentados para cada município da RMM nos anos de 2010 e 2016. Para isso, foram usadas duas fontes de dados. O número de matrículas foi calculado a partir do Censo Escolar/INEP, e a população na faixa etária correspondente foi obtida no Censo demográfico 2010 e nos parâmetros das projeções realizadas pelo IBGE para o ano de 2016 no estado do Paraná (IBGE, 2016). Nesse estudo, que focalizou a garantia do acesso, a TEL foi calculada a partir do número de crianças nas faixas etárias correspondentes à creche e à pré-escola sem considerar o segmento da educação infantil em que as crianças estavam efetivamente matriculadas. Esse critério visou retirar eventuais distorções decorrentes de critérios (ou erros) de classificação das crianças nas turmas de creche e pré-escola e garantir maior comparabilidade dos resultados entre municípios.

$\mathrm{O}$ 'percentual de variação das matrículas' é um indicador que analisa a evolução das matrículas no período 2010-2016. Entre os quatro indicadores utilizados, é o mais acessível do ponto de vista metodológico, uma vez que é calculado a partir do número de matrículas do Censo Escolar - levantamento anual realizado pelo Inep - e não depende de referência populacional. Para calcular o valor, basta aplicar a fórmula que calcula o incremento ou redução no número de matrículas entre o ano de comparação (tn) e o ano inicial do período em análise (t0), conforme quadro 1.

Por fim, o indicador da 'demanda por novas turmas' informa o número de turmas que deve ser ampliado para garantir a universalização da oferta. Esse indicador depende de um padrão de referência quanto ao número máximo de crianças por turma. Por não existir um parâmetro legal ou consensual, nesse estudo, a matriz de cálculo do Custo Aluno-Qualidade Inicial (Campanha Nacional pelo Direito à Educação, 2010) foi tomada como referência. Essa matriz adotou o parâmetro de até 12 crianças por turma na creche e até 22 na pré-escola. A partir da definição do parâmetro, o número de matrículas a ser ampliado em cada etapa foi dividido pelo número máximo de crianças por turma correspondente aos segmentos da educação infantil.

É importante salientar que, embora os indicadores 'taxa de atendimento' e TEL analisem o mesmo aspecto (o acesso à educação), na verdade, eles fornecem informações distintas e complementares. Por isso, como se verificará nas tabelas 1 e 2 nas seções seguintes, as taxas nem sempre são correlacionadas. Em alguns contextos, os números de ambas podem ser quase idênticos. Já em outros, podem ser muito distintos. Isso ocorre por diferentes razões. E é importante lembrar que, em se tratando de educação infantil, a não ser por erro dos sistemas de ensino, não há o que se falar em distorção idade-série, fenômeno tipicamente captado pela TEL nas etapas em que o "atraso" escolar (devido à reprovação e abandono) é 
possível. Entretanto, há situações em que a taxa de atendimento pode ser superestimada para a faixa etária de 0 a 3 anos, se as famílias/responsáveis responderem ao IBGE que a criança frequenta creche, quando, na verdade, ela fica em casa de cuidadores. Em uma situação como essa, a criança não faz parte dos registros do sistema de ensino e a TEL poderia sinalizar a ocorrência desse tipo de situação indesejada do ponto de vista de garantia do direito à educação das crianças em condições de qualidade. Outra situação captada somente pela análise conjunta dos dois indicadores seria, por exemplo, uma localidade em que a taxa de atendimento de 4 a 5 anos informa que o acesso não foi universalizado ( $90 \%$, por exemplo), mas a TEL é superior a $100 \%$. Nesse cenário, uma das hipóteses prováveis é que o município está matriculando crianças de municípios vizinhos (e, por isso, pode chegar a ter mais matrículas do que população em determinada faixa etária) e não tem conseguido universalizar o acesso para sua própria população.

Ainda em relação aos resultados da TEL, foram tomadas duas decisões metodológicas determinantes para os resultados apresentados na próxima seção. A primeira teve efeito no número de matrículas utilizado para calcular o indicador nos anos de 2010 e 2016. Como a data de referência do Censo 2010 foi $1^{\circ}$ de agosto, por consequência, a idade das crianças (em anos completos) na base do Censo/IBGE é a idade na data de referência da pesquisa ${ }^{8}$. Assim, para aumentar a precisão da TEL, as matrículas do Censo Escolar/Inep foram recalculadas para $1^{\circ}$ de agosto ${ }^{9}$. A não utilização desse procedimento poderia alterar consideravelmente os resultados para alguns municípios.

A segunda decisão é referente à projeção da população de 0 a 5 anos em cada município analisado para o ano de 2016. Como não houve contagem populacional em 2016, foi aplicado o fator de projeção calculado pelo IBGE para o grupo etário de 0 a 4 anos $^{10}$ do Paraná à população de 2010 para compor a população de 0 a 3 anos e 4 e 5 anos de cada município da RMM em 2016. Segundo o IBGE $(2016)^{11}$, houve uma redução na população de 0 a 4 anos do Paraná da ordem de $8,04 \%$

8 A variável do Censo 2010 utilizada foi a V6036 - Idade calculada em anos: idade da pessoa em anos completos na data de referência da pesquisa (ou seja, 01/08/2010).

9 As idades das crianças matriculadas foram recalculadas a partir das variáveis 'dia' e 'mês' de nascimento disponíveis nos microdados do Censo Escolar. Utilizando o software IBM SPSS Statistics, foi possível recalcular a idade em anos completos para as crianças que fizeram aniversário até $01 / 08 / 2010$.

10 O IBGE faz projeção para 19 grupos etários. Eles são diferentes das faixas etárias relativas às etapas (e segmentos de etapa) de ensino. O primeiro grupo etário projetado pelo IBGE é 0 a 4 anos e o último é de 90 anos ou mais.

11 Ver "Projeção da população do Brasil e Unidades da Federação por sexo e idade para o período 2000-2030 - Estado no Paraná” atualizada em 2016. Disponível em: https://ww2.ibge.gov. $\mathrm{br} /$ home/estatistica/populacao/estimativa2016/default.shtm 
no período de 2010 a 2016. Em termos práticos, foi adotada a suposição de que houve essa mesma dinâmica populacional para as faixas etárias de 0 a 3 anos e 4 e 5 anos nos 26 municípios analisados.

\section{A educação infantil na região metropolitana de Maringá: uma análise sobre a desigualdade de acesso}

A aprovação do PNE em 2014 significou um avanço no que diz respeito à legitimidade da Educação Infantil como primeira etapa da Educação Básica, conquista de mais de 20 anos, desde a aprovação da LDB em 1996. A Educação Infantil constitui a meta 1 do plano em sua integralidade. Nessa meta são estabelecidos percentuais de atendimento para creche e pré-escola, com prazos e estratégias definidos.

Quanto à definição dos percentuais de atendimento, há um amplo debate na área sobre a escolha pela universalização da Educação Infantil na pré-escola até 2016 e a ampliação da cobertura de no mínimo 50\% em creche para a população de 0 a 3 anos até 2024. Em primeiro lugar, a justificativa para a compulsoriedade de matrícula para a pré-escola se coloca por força da lei. A EC 59 de 2009 estabeleceu a educação básica obrigatória e gratuita dos 4 aos 17 anos e definiu a implementação progressiva, até 2016, nos termos do Plano Nacional de Educação, com apoio técnico e financeiro da União.

O ponto de maior polêmica é a definição da ampliação do atendimento em até no mínimo 50\% para a creche. Isso porque, como afirmam Campos, Spósito e Gimenes (2014), a definição desse percentual de atendimento não está baseada em um diagnóstico da cobertura que a fundamente. Ainda apontam o problema de sequer haver uma avaliação sobre o que levou ao não cumprimento da meta de 30\% de atendimento em creche definida no plano anterior (PNE 2001-2010).

Além do limite da ausência de um diagnóstico que permitisse identificar a viabilidade do cumprimento da meta, ainda lidamos com o fato de que a creche não possui obrigatoriedade de matrícula, embora desde a Constituição de 1988 seja um direito da criança, uma escolha da família e a sua oferta um dever do Estado (BRASIL, 1988). Em 2015, segundo dados da PNAD, os responsáveis por $61,8 \%$ das crianças menores de 4 anos que não estavam matriculadas em creche tinham interesse em matriculá-las (IBGE, 2017). Esse percentual representa 4,7 milhões de crianças em todo o Brasil. Tal fato corrobora a relevância social da creche que, ao atuar na educação e cuidado de crianças pequenas, cria uma condição favorável às famílias, em especial às mulheres, para que desenvolvam 
suas atividades, sobretudo as vinculadas ao trabalho, incidindo na diminuição das múltiplas desigualdades, como a econômica, de gênero e geracional.

Nesse sentido, definir $50 \%$ de atendimento pode confrontar diretamente com o direito que $100 \%$ das crianças de 0 a 3 anos possuem de frequentar a creche, enquanto pode superestimar a demanda, a depender do contexto, entende-se que a definição de uma meta com abrangência nacional se faz necessária dada a desigualdade de oferta identificada no país que, em 2015, tinha uma taxa de atendimento de apenas $30,39 \%$ em creche e de $90,45 \%$ para pré-escola ${ }^{12}$. Nesse ponto, é importante ressaltar que a desigualdade afeta a liberdade real dos indivíduos e é determinada a partir do seu pertencimento:

Uma desigualdade seria aquele tipo específico de diferença que consiste em uma distribuição social ou institucional que concede vantagens e desvantagens (benefícios, prejuízos ou cargas) que afetam a liberdade real dos indivíduos sobre a base de determinadas ações, estados ou características de origem social e/ou natural (NOGUERA, 2004, p. 6).

A desigualdade, nesse sentido, atua na privação da liberdade, sendo várias as formas de sua efetivação quando as pessoas não acessam seus direitos civis. Segundo Sen (2010), as liberdades políticas e civis são elementos constitutivos da liberdade humana, portanto não assegurá-los é uma deficiência do Estado. Outro aspecto importante no papel do Estado na garantia da liberdade política e civil das pessoas relaciona-se com a expansão das capabilities. Para o autor, as capacidades podem ser aumentadas pela política pública, ao mesmo tempo em que a capacidade participativa influencia as políticas públicas (SEN, 2010).

Podemos entender que o PNE é um elemento importante para a garantia da liberdade substantiva, ou seja, para a valorização do lugar de agente do sujeito, "[...] como membro público e como participante de ações econômicas, sociais e políticas" (SEN, 2010, p. 34). Contudo, o documento, por si só, não é capaz de garantir tal condição e outras ações sociais e políticas são

12 De acordo com o Laboratório de Dados Educacionais a partir de dados da Pnad (arquivo Pessoas)/IBGE 2015. Disponível em: https://dadoseducacionais.c3sl.ufpr.br/\#/indicadores/ atendimento 
necessárias. Nesse caso, destacamos ações de monitoramento da efetivação do que define o PNE.

Nessa perspectiva, deve-se considerar que as desigualdades são fruto de interações que podem atuar para a sua superação ou, ao contrário, para a sua expansão. No Brasil, identificamos um conjunto de desigualdades estruturais que estão na base da constituição da sociedade e que nela permanecem pelo prevalecimento econômico, social e político de alguns grupos e marginalização de grupos minoritários, dentre eles os pobres, as crianças, as mulheres, os negros.

As interações dentro dos campos sociais incidem sobre as desigualdades. As capacidades individuais se entrelaçam com as regras, com os dispositivos de poder, com os processos culturais e com todas as demais tramas institucionais que organizam os espaços. [...] Além disso, o funcionamento repetido dos campos de interação incide sobre os indivíduos, provocando que as capacidades de certos grupos se fortaleçam enquanto a de outros se debilitam, se consolidando assim as desigualdades persistentes, porque aparentam ser resultado dos méritos das pessoas (REYGADAS, 2004, p. 16).

O acesso à Educação Infantil, especialmente à creche, é um caso clássico de desigualdade no nosso país. Assim, faz-se necessário identificar quais desigualdades estão presentes em diferentes contextos, no sentido de criar mecanismos de monitoramento do cumprimento da meta 1 e subsidiar os municípios no planejamento da ampliação da oferta de vagas na Educação Infantil. Esse artigo apresenta uma contribuição nesse sentido, ao analisar a realidade relativa a uma microrregião em específico.

Desse modo, os números da tabela 1 revelam a desigualdade da realidade da população de crianças de 0 a 3 anos em diversos aspectos nos 26 municípios da RMM. Inicialmente, é importante notar que se trata de municípios muito díspares quanto ao porte medido pelo tamanho da população. Grande parte deles, segundo dados do Censo 2010, tinha menos de 10 mil habitantes (nove com até 5 mil habitantes; e seis entre com mais de 5 até 10 mil). Sarandi com 82 mil e Maringá com 357 mil habitantes eram, destacadamente, os mais populosos. De forma geral, a população total nesses municípios cresceu de 2010 a 2016 (assim como em todo o Paraná e no país). Todavia, houve redução nas faixas etárias da educação infantil (da ordem de $8 \%$ no Paraná). Esse fenômeno é típico da transição etária pela qual o Brasil está passando desde o final da década de 1990 e continuará até 2050. Essa transição é caracterizada pelo "envelhecimento" da 
população devido à queda da taxa de fecundidade e aumento da expectativa de vida da população.

Quanto ao desafio da meta 1 do PNE 2014-2024 e da garantia do direito à educação para todas as crianças, a tabela 1 mostra que os municípios da região de Maringá têm realidades muito distintas. A taxa de atendimento revela que em 2010 havia contextos díspares como o de Munhoz de Melo, um município com 132 crianças na faixa etária de 0 a 3 anos em que 70,2\% delas, segundo as famílias, estavam frequentando a creche; e, no outro extremo, o município de Nova Esperança com uma taxa de 17,4\%. Em conjunto, os municípios da RMM apresentavam um atendimento de $38 \%$, bem acima do estado do Paraná (26,2\%). Porém, seis municípios (todos de pequeno porte) estavam acima da meta de 50\% de atendimento. Maringá apresentava uma taxa de 47\%. Os maiores desafios estavam colocados para sete municípios que apresentavam taxas de atendimento de até 25\% (Jandaia do Sul, Paiçandu, Marialva, Cambira, Bom Sucesso, Ourizona e Nova Esperança), ou seja, abaixo do número geral do Paraná. Os números da taxa de matrícula líquida estão fortemente correlacionados com a taxa de atendimento (índice de correlação de $0,92^{13}$ ). É importante salientar que a TEL considera as crianças matriculadas no município e que, o fato de uma criança residir em um município e frequentar creche ou escola em município vizinho, fenômeno que ocorre em várias regiões metropolitanas do Brasil, faz com que os números da TEL se distanciem da taxa de atendimento. Em alguns contextos, principalmente em municípios de pequeno porte, a TEL pode ultrapassar 100\% (o que expressa que o sistema educacional local tem mais matrículas em determinada faixa etária do que população). Esses fenômenos são percebidos na mesma RMM para a população de 4 e 5 anos (vide tabela 2).

A tabela 1 também mostra a evolução do acesso na RMM no período 20102016. Houve um crescimento de 5.099 matrículas para as crianças de 0 a 3 anos (aumento de $40 \%$ ). Esse percentual está um pouco abaixo do verificado no estado do Paraná como um todo $(43,1 \%)$. Com vistas à redução da desigualdade na RMM, ao analisar a TEL 2010 e a taxa de evolução (crescimento) de matrículas 2010-2016, seria desejável uma forte correlação negativa, o que denotaria que os municípios com menores TEL em 2010 obtiveram maior crescimento na matrícula no período (esse seria o movimento necessário para reverter a situação de baixo atendimento). Isso ocorreu somente para sete municípios que tinham TEL de até $30 \%$ em 2010 e fizeram um crescimento de $42,2 \%$ a $109,3 \%$ no período. Mas há

13 Foi utilizado o índice de correlação de Pearson; medida que expressa a correlação entre duas variáveis em uma escala de -1 (correlação negativa perfeita) até +1 (correlação positiva perfeita). Correlações próximas de zero indicam ausência de correlação entre as variáveis. 


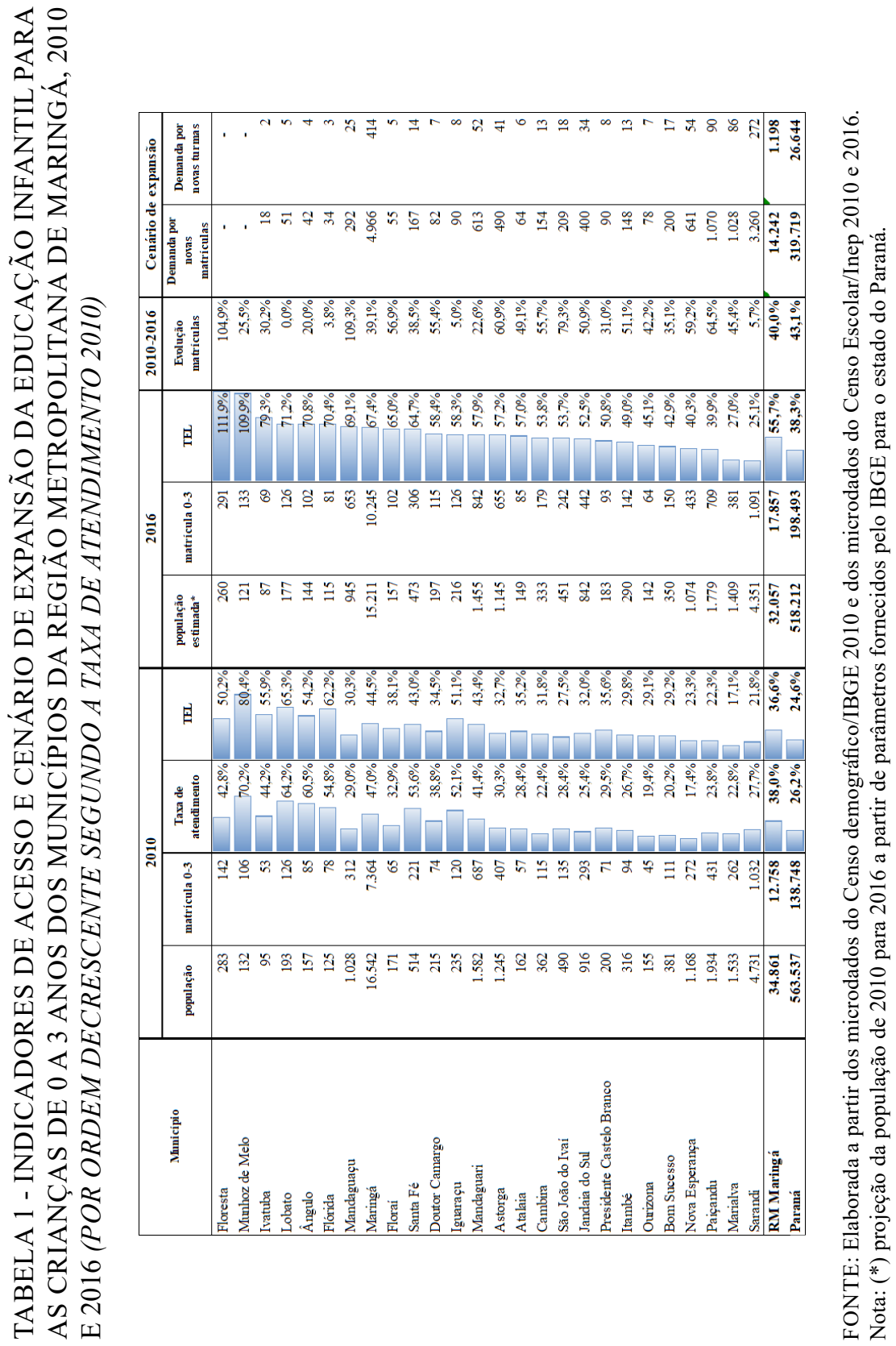


casos como Sarandi que tinha uma TEL de $21,8 \%$ em 2010 e as matrículas cresceram apenas 5,7\% no período. A TEL de 2016, ainda que tenha sido calculada com uma população estimada, sugere que apenas dois municípios universalizaram o acesso para crianças de 0 a 3 anos (Floresta e Munhoz de Melo); quatro outros estão com as taxas na casa dos 70\% (Ivatuba, Lobato, Ângulo e Flórida); 13 municípios estão acima da meta 1 do $\operatorname{PNE}(50 \%)$ e abaixo dos 70\%; e outros sete não atingiram a meta 1, sendo que dois (Marialva e Sarandi) não chegaram a $30 \%$. De toda maneira, conclusões quanto à universalização do acesso à creche a partir da TEL 2016 nos municípios de Floresta e Munhoz de Melo devem ser cautelosas. Novas análises são necessárias, uma vez que pode haver erro na estimativa da população de 2016. Mas é importante reconhecer os esforços de expansão nas matrículas da ordem de 104,9\% e 25,5\%, respectivamente, nesses municípios de 2010 a 2016.

É interessante notar que a alta correlação positiva $(0,82)$ entre as TEL de 2010 e 2016 evidencia a manutenção da situação dos municípios quanto ao nível de atendimento em relação aos demais (os que tinham baixo atendimento permaneceram com os menores e, os que tinham alto, permaneceram em maior nível) no período 2010-2016, apesar da expansão de 40\% no número de matrículas (ou seja, da criação de 5.088 novas vagas). Além disso, apesar do crescimento de $36,6 \%$ para $55,7 \%$ da TEL da RMM, os números da tabela 1 mostram que a desigualdade não reduziu na mesma proporção (o coeficiente de variação das TEL de 2010 e 2016 reduziu apenas de 39\% para 34\% no período).

As causas para a evolução de matrículas tão distinta nos diferentes municípios da microrregião podem ser diversas e necessitam de um estudo específico para a sua compreensão. Contudo, é possível considerar alguns interferentes que podem afetar as políticas de acesso às creches implementadas pelos municípios. Um deles é a ausência de dados sobre a demanda real por creche. De modo geral, os municípios consideram a demanda por creche a partir da demanda explícita, ou seja, aquela registrada pela família ao buscar uma vaga na creche. Mas, a demanda explícita, geralmente identificada por meio de 'listas de espera', não revela a real demanda por vaga. Rosemberg define o que é demanda e diferencia a demanda explícita da latente. De acordo com a autora: 
A demanda é uma necessidade sentida e expressa. Ela pode ser explícita ou latente: a explícita é avaliada através da procura de um serviço. A demanda latente é aquela que não se expressa espontaneamente, por alguma razão (distância entre domicílio e equipamento, qualidade ou tipo de serviço oferecido etc.). A única forma de aferição da demanda latente é a realização de enquetes específicas (ROSEMBERG, 2001, p. 25).

A diferenciação apresentada pela pesquisadora amplia a compreensão sobre as formas de aferição da demanda e reforça a necessidade de realização de enquetes sobre o interesse de matricular as crianças de 0 a 3 anos na creche e da busca ativa junto às famílias por parte do poder público municipal. A estratégia 1.3 do PNE indica essa necessidade ao orientar que se deve "realizar, periodicamente, em regime de colaboração, levantamento da demanda por creche para a população de até três anos, como forma de planejar a oferta e verificar o atendimento à demanda manifesta" (BRASIL, 2014, p. 3).

Essa busca ativa também se faz necessária para a matrícula na pré-escola, pois, mesmo que em 2016 o prazo para a universalização tenha expirado, em muitos contextos, as prefeituras não ofertaram vagas suficientes e/ou as famílias não matricularam as crianças de 4 e $5 \operatorname{anos}^{14}$. No que tange as estratégias para identificação de demanda para a pré-escola, o texto do PNE não é tão claro, como é possível notar na estratégia 1.16 que determina que o "Distrito Federal e os Municípios, com a colaboração da União e dos Estados, realizarão e publicarão, a cada ano, levantamento da demanda manifesta por educação infantil e pré-escolas" (BRASIL, 2014, p. 3). O texto da estratégia utiliza os termos "educação infantil e pré-escolas", sendo que a segunda é parte da primeira. Além disso, remete apenas à identificação da demanda manifesta e ignora a importância do mapeamento da demanda latente, levantamento fundamental, visto a imprecisão dos dados quanto ao número total de crianças.

Ao analisar a evolução das matrículas entre 2010-2016, parece-nos fundamental que os municípios cumpram a tarefa solicitada por Rosemberg (2001) e busquem identificar junto às famílias com crianças pequenas ou que estão para nascer o interesse em matriculá-las em uma creche pública. Outra

14 A esse respeito ver o Relatório Geral da Auditoria na Educação Infantil (2016) elaborado pelo Tribunal de Contas do Estado do Paraná. Esse documento relata que apenas $32,5 \%$ dos 40 municípios de pequeno porte do estado do Paraná auditados universalizou o atendimento das crianças de 4 e 5 anos em pré-escola até 2016. 


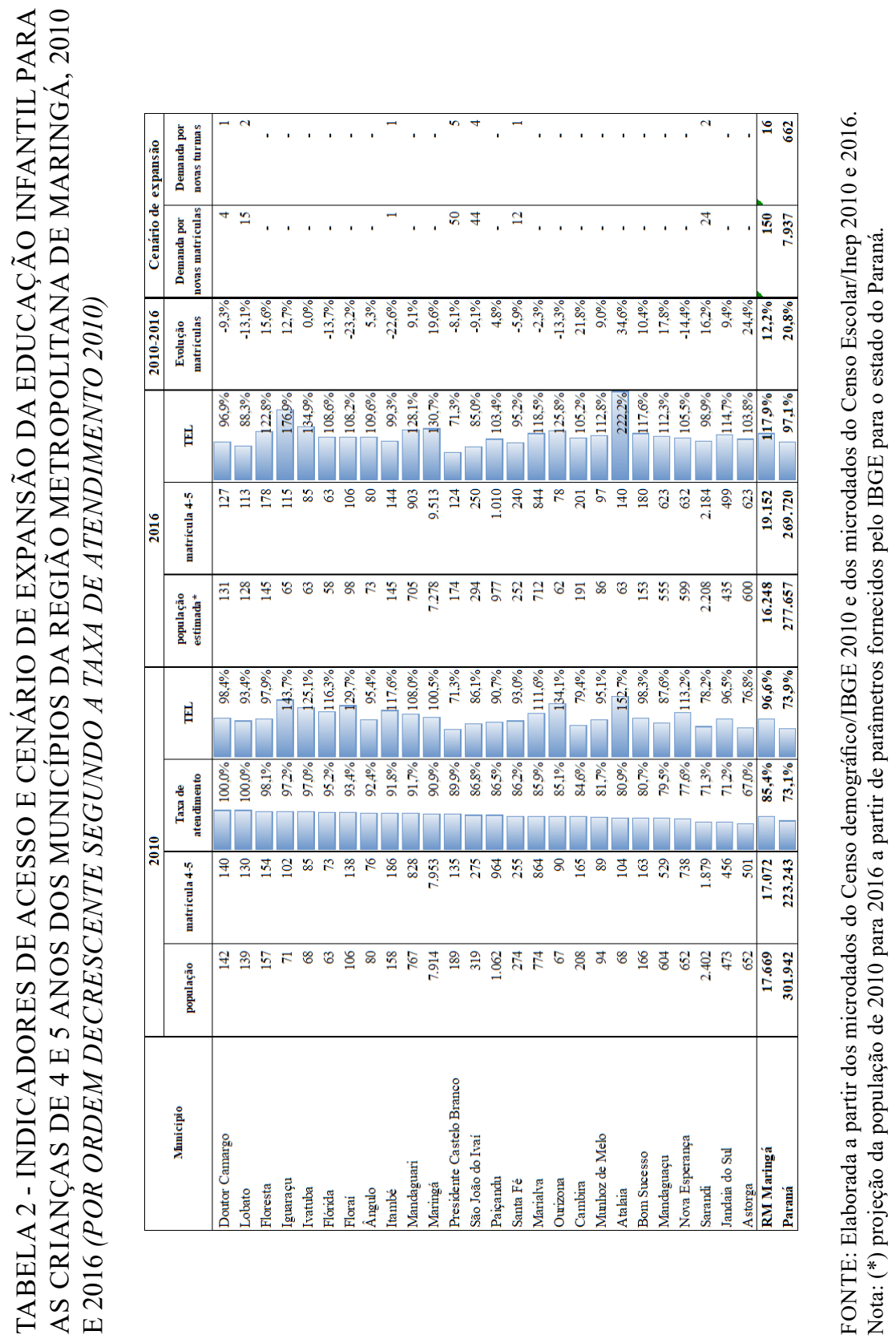


tarefa é a organização da lista de espera, que em muitos casos se limita a ficar exposta na própria instituição. É necessário que a lista seja única e pública, pois é direito das famílias e da sociedade de modo geral ter acesso aos dados da demanda e do seu atendimento. Além do que, esse é um mecanismo de controle social quanto à responsabilidade ${ }^{15}$ do Estado em ampliar o acesso à educação infantil.

Cabe ainda destacar que a ampliação do atendimento deve ocorrer a partir de um planejamento baseado em estudos sobre demanda e cabe aos municípios que já atendem um percentual superior aos $50 \%$ ampliar as vagas para atender todas as crianças que as famílias optarem pela frequência à creche. Para isso, faz-se necessário desenvolver mais pesquisas acadêmicas e inquéritos com as famílias sobre demanda para realizar planejamentos a longo prazo de oferta pública, gratuita e com qualidade.

Nessa perspectiva, a tabela 1 ainda apresenta o esforço para universalização do acesso à creche para crianças de 0 a 3 anos. Ao todo, seria necessário ofertar 14.242 novas vagas em creche, o que, adotando o critério utilizado pela Campanha Nacional pelo Direito à Educação de no máximo 12 crianças por turma, sugere a abertura de 1.187 novas turmas nos municípios da RMM. O número de turmas varia fortemente entre os municípios (de 2 a 414), de acordo com o tamanho da população e a TEL alcançada em 2016. A demanda por novas turmas, seguramente, terá impacto no financiamento da educação local, pois requererá a construção de novos estabelecimentos em pelo menos 18 municípios da região (aqueles que demandam mais de cinco novas turmas) e a contratação de cerca de 2.374 professores (se considerarmos que em cada nova turma terá dois profissionais). A tabela 2 apresenta os números para a faixa etária de 4 e 5 anos.

A análise do acesso à educação das crianças de 4 e 5 anos da RMM deve ocorrer não somente à luz da meta 1 do PNE 2014-2024, mas também deve considerar a Emenda Constitucional $n^{0} 59 / 2009$ e a Lei ${ }^{\circ} 12.796 / 2013$ que alteraram a faixa etária da educação básica obrigatória de 6 a 14 anos para 4 a 17 anos e que, portanto, antes da sanção da Lei 13.005/2014, colocaram a universalização do acesso para essa faixa etária na pauta das redes de ensino. Em 2010, a taxa de atendimento das crianças de 4 e 5 anos na RMM, como um todo, era de $85,4 \%$ (acima da taxa do estado do Paraná: 73,1\%). Mas a realidade não era homogênea entre os 26 municípios da região. Os municípios de Lobato e Doutor Camargo já tinham atingido uma taxa de $100 \%$ e outros nove tinham

15 Para atender $50 \%$ das crianças de 0 a 3 anos nos 26 municípios da RMM, conforme a meta 1 do PNE 2014-2024, seria necessário ofertar 1.729 novas vagas e 148 novas turmas. 
mais de $90 \%$ de atendimento. Por outro lado, municípios como Jandaia do Sul, Astorga e Sarandi apresentavam um atendimento entorno de $70 \%$.

Vale notar que há discrepância entre a taxa de atendimento e a TEL em 2010 (isso é confirmando pela baixa correlação entre os dois indicadores = 0,304). Um exemplo é o caso de Nova Esperança que apresenta uma taxa de atendimento de $77,6 \%$ e uma TEL de $113,2 \%$. Embora na realidade isso possa ocorrer, sobretudo para municípios com número reduzido de matrículas, esse número suscita análises locais mais detalhadas. Os números da TEL 2010 indicavam que 11 municípios (inclusive Maringá) já tinham universalizado o acesso. A TEL indica também que em sete deles, todos com uma população de 4 e 5 anos muito pequena (menos de 100 crianças), têm mais matrículas na faixa etária do que população. Por isso, apresentam valores acima de 100\%. Sarandi, Astorga e Presidente Castelo Branco figuravam entre os municípios com menores TEL em 2010. Já em 2016, a TEL indica que 19 municípios atingiram a universalização do acesso. Vale destacar sete municípios que expandiram suas matrículas em mais de $15 \%$ no período: Atalaia (34,6\%), Astorga (24,4\%), Cambira (21,8\%), Maringá (19,6\%), Mandaguaçu (17,8\%), Sarandi (16,2\%) e Floresta (15,6\%). Em situação oposta, estão municípios que não atingiram a universalização e que reduziram o número de matrículas no período: Doutor Camargo (-9,3\%), Lobato (-13,1\%), São João do Ivaí (-9,1\%) e Presidente Castelo Branco (-8,1\%). A TEL do município de Presidente Castelo Branco se manteve estável em 71,3\% nos dois anos observados.

Em suma, os números da tabela 2, considerando os critérios e suposições para projetar a população de cada município de 2010 para 2016, sugerem que, com o aumento de 2.080 matrículas (expansão de 12,2\%), o desafio para a universalização na faixa etária de 4 e 5 anos na RMM foi cumprido por quase todos os municípios em 2016. A conclusão da universalização demandaria 150 novas vagas e, considerando o número máximo de 22 crianças por turma, demandaria a abertura de 16 novas turmas distribuídas em cinco municípios. Ou seja, um esforço consideravelmente menor do que para a universalização para a faixa de 0 a 3 anos.

Mas, ainda que o cumprimento da universalização da matrícula na pré-escola se revele como desafio menos complexo, faz-se necessário avançar no debate sobre as concepções de infância e educação infantil e sobre as condições da oferta que devem orientar o cumprimento da meta 1. Esse debate está ausente no PNE, o que é preocupante, uma vez que ainda predomina uma concepção de educação para as crianças de 4 a 5 anos assentada em uma perspectiva "escolar" com práticas pedagógicas que visam prepará-las para a etapa seguinte (ensino fundamental). Nesse sentido, o atendimento à meta pode fortalecer essa perspectiva, a depender das estratégias utilizadas pelos munícipios. 
Moss (2011), ao tratar da relação entre Educação Infantil e ensino obrigatório nos países membros da Organização para Cooperação e Desenvolvimento Econômico (OCDE), destaca três fatores interligados: o crescimento e a presente expansão dos serviços de educação infantil, especialmente nos dois ou três anos que precedem o ensino obrigatório; os benefícios aparentes da educação infantil que ganharam visibilidade e chamaram a atenção dos elaboradores de políticas públicas; e o argumento defendido por economistas de que o investimento educacional mais produtivo é aquele feito nas crianças com idade inferior a do ingresso no ensino obrigatório.

Ao tomar por base o relatório da OCDE, o autor ainda destaca que a parceria entre a educação infantil e o ensino obrigatório pode ser favorável, mas também pode incorrer em riscos, principalmente o de

[...] "levar a uma abordagem escolar na organização dos serviços de educação infantil"; e que tal pressão por parte das escolas possa levar as instituições de educação infantil a "adotar conteúdos e metodologia da escola primária", com efeito "prejudicial na aprendizagem das crianças pequenas" (OCDE, 2001, p. 129 apud MOSS, 2011, p. 146).

O risco da subordinação ganha maior amplitude quando a pré-escola passa a figurar como parte da educação obrigatória, o que exige monitorar não só o cumprimento da obrigatoriedade de matrícula, mas também as condições de oferta, o que implica em identificar em quais instituições as vagas foram ofertadas (instituições próprias para a educação infantil ou compartilhadas com outras etapas e modalidades) e a sua estrutura; o número de crianças por turma; os profissionais que atuam com essas turmas e na gestão das instituições; a jornada (parcial ou integral); o currículo e os processos de avaliação.

O monitoramento do cumprimento da universalização da pré-escola e a análise das condições de oferta atuam na defesa da obrigatoriedade como mecanismo que assegura o direito das crianças de 4 e 5 anos a uma educação pública e de qualidade, assim como o caráter específico dessa oferta a partir do que constitui a etapa Educação Infantil e não a sua subordinação a etapas subsequentes. 


\section{Considerações finais}

O objetivo deste artigo é problematizar o tamanho do desafio dos $26 \mathrm{mu}-$ nicípios que compõem a RMM, no estado do Paraná, para cumprir a meta 1 do PNE. Nessa perspectiva, a partir da análise dos dados, pôde-se observar que um dos desafios é a grande desigualdade quanto à oferta de vagas, principalmente para as crianças de 0 a 3 anos, em grande parte dos municípios.

Os dados mostram que, com uma expansão de 5.099 matrículas (40\%) para crianças de 0 a 3 anos e 2.008 matrículas $(12,2 \%)$ para crianças de 4 e 5 anos no período de 2010 a 2016, com base na TEL, grande parte dos municípios estavam próximos do cumprimento da meta de universalização do atendimento para a população de 4 e 5 anos. Quanto ao atendimento para as crianças de 0 a 3 anos, os números sugerem que sete municípios estavam abaixo da meta de $50 \%$ definida no PNE.

De todo modo, é preocupante o quadro relativo à evolução das matrículas em alguns municípios. No município de Lobato, por exemplo, não houve ampliação. Essa localidade apresentava uma TEL de 65,3 \% em 2010 e de 71,2\% em 2016, mas, em números absolutos, atende a mesma quantidade de crianças (126), mas precisaria criar quatro turmas para atender a população total de 0 a 3 anos. Igualmente, em Maringá que, mesmo com uma evolução de matrículas da ordem de $39 \%$ entre 2010 e 2016, precisaria criar 414 turmas para atender toda a população de 0 a 3 anos.

Tais dados, bem como as TEL baixas em 2016, como a de Sarandi $(25,1 \%)$ e Marialva (27\%), remetem à necessidade de realizar novos estudos para analisar os fatores intervenientes da desigualdade de acesso para as crianças de 0 a 3 anos, quais sejam: capacidade de financiamento da educação nos municípios; valor do gasto-aluno; renda per capita das famílias das crianças; taxa de urbanização; número de crianças por turma.

O quadro diversificado identificado na RMM quanto ao atendimento das crianças de 0 a 5 anos reforça a importância do monitoramento das taxas de acesso para orientar o planejamento das redes. Como já destacado, um dos principais desafios para o monitoramento do alcance da meta 1 no nível de municípios é a inexistência de dados sobre o número de crianças nas faixas etárias específicas da educação infantil (creche: 0 a 3 anos e pré-escola: 4 e 5 anos). Portanto, é necessário que haja fontes de dados confiáveis sobre o tamanho da população nas faixas etárias relativas aos segmentos e etapas da educação básica.

Por fim, vale frisar que a efetivação do direito à Educação Infantil das crianças de 0 a 5 anos depende do planejamento e execução de políticas que ga- 
rantam o acesso, mas que também assegurem a qualidade das estruturas físicas ${ }^{16}$, a valorização dos profissionais e a adequada razão adulto-criança para possibilitar uma mediação que favoreça o desenvolvimento das crianças. Igualmente, são necessários currículos e processos de avaliação alinhados às definições presentes na LDB (Lei 9.394/1996) e às Diretrizes Curriculares Nacionais para a Educação Infantil (BRASIL, 2009a). Estudos para análise desses aspectos no processo de expansão do acesso à educação infantil são necessários, uma vez que a expansão em condições de qualidade exige um grande esforço por parte do poder público tanto para garantir recursos financeiros indispensáveis quanto no desenvolvimento e uso da capacidade administrativa e pedagógica das secretarias de educação. Além disso, demandam mobilização dos movimentos sociais e da sociedade na reinvindicação dos direitos e controle social das ações do Estado.

16 No que se refere à expansão do acesso e à qualidade da infraestrutura, destacamos o Programa Nacional de Reestruturação e Aquisição de Equipamentos para a Rede Escolar Pública de Educação Infantil (Proinfância), vinculado ao Plano de Desenvolvimento da Educação (PDE) e instituído pela Resolução/CD/FNDE n ${ }^{\circ} 6$, de 27 de abril de 2007. O objetivo do programa é prestar assistência técnica e financeira para municípios e o Distrito Federal, investindo na construção de creches e equipando-as. Sua implementação decorre da consideração da necessidade de promover ações supletivas e redistributivas, para a correção progressiva das disparidades de acesso e de garantia do padrão mínimo de qualidade de ensino, assim como de proporcionar à sociedade a melhoria da infraestrutura da rede física escolar de Educação Infantil. A ausência de dados sobre a real incidência do programa fez com que em 2018 o MEC iniciasse um levantamento junto aos municípios que tiveram alguma obra do Proinfância para avaliar os seus resultados, o funcionamento das unidades e fornecer subsídios para planejamentos e execuções de ações de suporte. 


\section{REFERÊNCIAS}

BRASIL. Constituição da República Federativa do Brasil. Brasília: Congresso Nacional, 1988.

. Lei $n^{\circ}$. 9.394, de 20 de dezembro de 1996. Estabelece as Diretrizes e Bases da Educação Nacional. Brasília, 1996.

. Instituto Nacional de Estudos e Pesquisas Educacionais Anísio Teixeira (INEP). Dicionário de Indicadores Educacionais, Brasília: Inep, 2004.

. Resolução CD/FNDE $n^{\circ}$, de 24 de abril de 2007. Estabelece as orientações e diretrizes para execução e assistência financeira suplementar ao Programa Nacional de Reestruturação e Aquisição de Equipamentos para a Rede Escolar Pública de Educação Infantil - PROINFÂNCIA. Brasília: Conselho Deliberativo do Fundo Nacional de Desenvolvimento da Educação, 2007.

. Emenda Constitucional $n^{\circ} 59$, de 11 de novembro de 2009. Acrescenta $\S 3^{\circ}$ ao art. 76 do Ato das Disposições Constitucionais Transitórias para reduzir, anualmente, a partir do exercício de 2009, o percentual da Desvinculação das Receitas da União incidente sobre os recursos destinados à manutenção e desenvolvimento do ensino de que trata o art. 212 da Constituição Federal, dá nova redação aos incisos I e VII do art. 208, de forma a prever a obrigatoriedade do ensino de quatro a dezessete anos e ampliar a abrangência dos programas suplementares para todas as etapas da educação básica, e dá nova redação ao $\S$ $4^{\circ}$ do art. 211 e ao $\S 3^{\circ}$ do art. 212 e ao caput do art. 214 , com a inserção neste dispositivo de inciso VI. Presidência da República. Brasília, DF, 2009.

. Resolução CNE/CEB n 05, de 17 de dezembro de 2009. Fixa as Diretrizes Curriculares Nacionais para a Educação Infantil. Conselho Nacional da Educação, Câmara da Educação Básica. Brasília, DF, 2009a.

. Lei $n^{\circ} 13.005$, de 25 de junho de 2014. Aprova o Plano Nacional de Educação - PNE e dá outras providências. Brasília, 2014.

. Lei $n^{\circ} 12.796$, de 4 de abril de 2013. Altera a Lei no 9.394, de 20 de dezembro $\overline{\text { de } 1996}$, que estabelece as diretrizes e bases da educação nacional, para dispor sobre a formação dos profissionais da educação e dar outras providências. Brasília, 2014.

. Instituto Nacional de Estudos e Pesquisas Educacionais Anísio Teixeira (INEP). Relatório de Monitoramento do $1^{\circ}$ ciclo das Metas do Plano Nacional de Educação: biênio 2014-2016, Brasília: Inep, 2016.

. Instituto Nacional de Estudos e Pesquisas Educacionais Anísio Teixeira (INEP). Relatório de Monitoramento do $2^{\circ}$ ciclo das Metas do Plano Nacional de Educação 2018, Brasília: Inep, 2018.

Campanha Nacional Pelo Direito à Educação. Educação Pública de Qualidade: quanto 
custa esse direito? São Paulo: Campanha Nacional pelo Direito à Educação, 2010.

CAMPO, M. M; ESPOSITO; Y, L; GIMENES, N, A, S. A meta 1 do Plano Nacional de Educação Observando o presente de olho no futuro. In: Revista Retratos da Escola, Brasília, v. 8, n. 15, p. 329-352, jul./dez. 2014.

IBGE. Fundação Instituto Brasileiro de Geografia e Estatística (IBGE). Estimativas populacionais para os municípios e para as Unidades da Federação brasileiros em 01.07.2016. Rio de Janeiro: IBGE, 2016. Disponível em: https://ww2.ibge.gov.br/home/ estatistica/populacao/estimativa2016/default.shtm. Acesso em: 24 fev. 2018.

. Fundação Instituto Brasileiro de Geografia e Estatística (IBGE). Aspectos dos cuidados das crianças de menos de 4 anos de idade: 2015. Rio de Janeiro: IBGE, 2017. Disponível em: https://biblioteca.ibge.gov.br/visualizacao/livros/liv100137.pdf. Acesso em: 15 ago. 2018.

JANNUZZI, P. M. Indicadores para diagnóstico, monitoramento e avaliação de programas sociais no Brasil. Revista do Serviço Público, Brasília, v. 56, n. 2, p. 137-160, abr./jun. 2005.

MOSS, P. Qual o futuro da relação entre educação infantil e ensino obrigatório? Cadernos de Pesquisa. v. 41, n. 142, jan./abr., 2011. Disponível em: http://www.scielo.br/scielo. php?pid=S0100-15742011000100008\&script=sci_arttext. Acesso em: 10 jan. 2014.

NOGUERA, J. A. Sobre el concepto de desigualdad en ciências sociales. 2004. Disponível em: http:/gsadi.uab.cat/images/pdfs/noguera/Sobre\%20el\%20concepto\%20de\%20 desigualdad\%20en\%20ciencias\%20sociales.pdf. Acesso em: 9 mai. 2017.

OECD. Organisation for Economic Co-operation and Development. Education at a Glance 2016: OECD Indicators. Paris: OECD Publishing, 2016. Disponível em: http:// dx.doi.org/10.187/eag-2016-en. Acesso em: 20 fev. 2018.

ROSEMBERG, F. Avaliação de programas, indicadores e projetos em educação infantil. In: Revista Brasileira de Educação, n. 16, p. 19-26, 2001.

REYGADAS, L. Las redes de la desigualdad: un enfoque multidimensional. Política y Cultura, n. 22, 2004, p. 7-25. Disponível em: http://www.redalyc.org/articulo. oa?id=26702202. Acesso em: maio de 2017.

SEN, A. Desenvolvimento como liberdade. Tradução de Laura Teixeira Mota. São Paulo: Companhia das Letras, 2010.

Texto recebido em 05 de dezembro de 2018.

Texto aprovado em 19 de março de 2019. 